\title{
Unmet need in chronic hepatitis B management
}

\author{
Lilian Yan Liang and Grace Lai-Hung Wong \\ Department of Medicine and Therapeutics, Prince of Wales Hospital, Hong Kong SAR, China
}

\begin{abstract}
Despite all these exciting developments, there remain some unmet needs in the management for patients with chronic hepatitis B (CHB). As majority of CHB patients are going to use oral nucleos(t)ide analogues (NAs) for decades, Safety profile of NAs is of no doubt an important issue. The newest nucleotide analogue tenofovir alafenamide is potent in terms of viral suppression, together with favourable renal and bone safety profile. Biochemical response as reflected by alanine aminotransferase (ALT) normalization is recently found to be prognostically important. Patients who achieved ALT normalization have reduced the risk of hepatic events by $49 \%$. Functional cure as reflected by hepatitis B surface antigen seroclearance not only implies patients may stop NA treatment, it also confers to a reduced risk of hepatocellular carcinoma and other hepatic events. Hence functional cure should be the ultimate treatment goal in CHB patients. Preemptive antiviral treatment may reduce mother-to-child transmission of hepatitis B virus, especially if birth dose of vaccination cannot be given in the first two hours after delivery. Lastly, despite the currently first-line NAs have highgenetic barrier to drug resistance mutations, there are still are many patients who were previously treated with low barrier of resistance including lamivudine, telbivudine or adefovir dipivoxil which could lead to antiviral resistance and affecting the choice of NAs. (Clin Mol Hepatol 2019;25:172-180)
\end{abstract}

Keywords: Hepatitis B; Cirrhosis; Hepatocellular carcinoma; Mortality; Tenofovir alafenamide

\section{INTRODUCTION}

Despite the universal vaccination for hepatitis B virus (HBV) in the last three decades, chronic HBV infection remains a considerable global health problem and approximately two billion people of the world population have been infected; of which an estimated 257 million people are living with HBV infection. ${ }^{1}$ Chronic hepatitis $B(C H B)$ is one of the leading causes of hepatocellular carcinoma (HCC), cirrhotic complications and liver-related death worldwide, especially in Asia-Pacific region where HBV remains highly prevalent. ${ }^{2}$ Antiviral treatment has been moving forward from conventional interferon to pegylated interferon and oral nucleos(t)ide analogues (NA) over the last three decades. The current first-line NA, including entecavir (ETV), tenofovir disoproxil fumarate (TDF) and tenofovir alafenamide (TAF), improve patient survival by reducing the risk of HCC and hepatic events in CHB patients. ${ }^{3,4}$ Currently, a number of novel therapies have entered clinical development aiming to achieve functional cure of $\mathrm{CHB}^{5}$ which is defined as hepatitis B surface antigen ( $\mathrm{HBsAg}$ ) seroclearance. $^{6-8}$ Despite all these exciting developments, there remain

\footnotetext{
Abbreviations:

AASLD, American Association for the Study of Liver Diseases; ADV, adefovir dipivoxil; ALT, alanine aminotransferase; anti-HBs, antibody to HBsAg; APASL, Asian Pacific Association for the Study of Liver; BMD, bone mineral density; CHB, chronic hepatitis $\mathrm{B} ; \mathrm{Cl}$, confidence intervals; $C K D$, chronic kidney disease; $E A S L$, European Association for the study of the Liver; eGFR, estimated glomerular filtration rate; ETV, entecavir; $\mathrm{HbA1c}$, haemoglobin A1c; $\mathrm{HBeAg}$, hepatitis B e antigen; HBlg, hepatitis B immunoglobulin; HBsAg, hepatitis B surface antigen; $\mathrm{HBV}$, hepatitis B virus; HCC, hepatocellular carcinoma; MDR, multidrug resistance; MTCT, mother-to-child transmission; NA, nucleos(t)ide analogues; TAF, tenofovir alafenamide: TDF, tenofovir disoproxil fumarate
}

Corresponding author : Grace Lai-Hung Wong

Department of Medicine and Therapeutics, Prince of Wales Hospital, 30 32 Ngan Shing Street, Hong Kong SAR, China

Tel: +852-3505-3996, Fax: +852-2637-3852

E-mail: wonglaihung@cuhk.edu.hk

https://orcid.org/0000-0002-2863-9389 
some unmet needs in the management for CHB patients. In this review article, we discussed several of these unmet needs and their potential solutions.

\section{UNMET NEED 1: IS LONG-TERM NA TREAT- MENT SAFE ENOUGH?}

Safety profile of NAs is of no doubt an important issue, because its use has been tremendously increased over the last two decades; and majority of CHB patients are going to use NAs for decades. ${ }^{9}$ Although NAs are generally safe and relatively free of major side effects, nephrotoxicity and bone toxicity may occur in a small yet non-negligible proportion of patients receiving some nucleotide analogues, e.g. adefovir dipivoxil (ADV) and TDF. ${ }^{10}$ Mechanisms of nucleotide analogue-associated nephrotoxicity include inhibition of tubular cell transport accumulation of endogenous compounds leads to toxicity in short term; and mitochondrial injury in long term." In fact even untreated CHB patients have substantial risk of chronic kidney disease (CKD) progression; the 5 -year cumulative incidence of CKD progression was 48\% in TDFtreated and $43 \%$ both in ETV-treated and untreated patients. ${ }^{12}$

\section{Renal safety}

The issue of nephrotoxicity by older generations of nucleotide analogues is going to fade out in the near future as a new generation of nucleotide analogue, TAF, has been approved in many parts of the world. The latest European Association for the study of the Liver (EASL) practice guidelines for CHB recommend TAF as the one of the first line NAs; TAF is preferred over TDF if a patient has or is at risk of renal or bone disease. ${ }^{6}$ With the similarly potent viral suppression, TAF was shown to have better renal and bone safety profile compared to TDF. ${ }^{13,14}$ At Week 96 of two Phase 3 studies of total 1,298 patients, TAF-treated patients had smaller declines in estimated glomerular filtration rate (eGFR) $(-2.4 \mathrm{~mL} /$ $\mathrm{min})$ than TDF-treated patients $(-6.7 \mathrm{~mL} / \mathrm{min} ; P=0.008) .{ }^{15}$ Fewer TAF recipients experienced a decline in eGFR $>25 \%$ ( $10 \%$ vs. $18 \% ; P=0.002)$ or had a confirmed eGFR of $<50 \mathrm{~mL} / \mathrm{min}(0 \%$ vs. $2 \% ; P=0.004){ }^{16}$ Patients on TDF at risk of development and/or with underlying renal (as well as bone) disease should be considered for a switch to ETV or TAF, depending on previous lamivudine exposure. ${ }^{6}$

\section{Bone safety}

Bone toxicity is closely related to NA effect on renal proximal tubular and phosphaturia. Real-life data demonstrated increased risk of hip fracture in patients received ADV but not TDF. ${ }^{9}$ Patients who received TAF had smaller declines in bone mineral density (BMD), particularly at the hip $(-0.28 \%)$ than those receiving TDF $(-2.16 \% ; P<0.001){ }^{17}$ Significantly fewer TAF than TDF recipients experienced a $>3 \%$ reduction in spine (25\% vs. $45 \%$ ) or hip ( $14 \%$ vs. $39 \%$ ) BMD over 96 weeks. ${ }^{17}$ Furthermore, improved bone (as well as renal) safety was observed in patients who switched from TDF to TAF from week 96 onwards. ${ }^{18}$ TAF may be the more ideal NA in CHB patients with underlying factors for osteoporotic fractures.

\section{Other safety}

Apart from renal and bone toxicities, there have been quite some data on other less commonly encountered side effects. ${ }^{9}$ There were always some concerns about the effect of antiviral treatment on the risks of non-liver cancers, as ETV shows potential carcinogenic effect in some early animal studies. A population-based study of 44,494 subjects in Hong Kong showed that NA-treated patients had similar risks of various common malignancies, in particular gastrointestinal, lung, urinary and renal malignancies, when compared to untreated patients. ${ }^{19}$ Muscular toxicity may be seen in telbivudine-treated patients so regular monitoring is advised; peripheral neuropathy and lactic acidosis are rare adverse events. ${ }^{9}$ Latest international guidelines support the use of TDF, telbivudine and lamivudine during pregnancy; breastfeeding is not contraindicated during TDF therapy. ${ }^{6,8}$ With more data from real-life cohorts of sufficiently large sample size and long follow-up durations, the long-term safety profile of NAs is now more clearly defined. CHB patients receiving NA treatment for years and even decades can be reassured that this treatment would bring them clinically beneficial effects with minimal side effects. This would be one of the key elements to ensure drug adherence in our CHB patients.

\section{UNMET NEED 2: HOW IMPORTANT IS ALANINE AMINOTRANSFERASE (ALT) NORMALIZATION?}

The importance of ALT normalization while on NA treatment has been under the spotlight recently. Elevated ALT above two 
times of the upper limit of normal in CHB patients is one of the key indication for antiviral treatment recommended by international guidelines. ${ }^{6-8}$ Normal on-treatment ALT is often regarded as biochemical response to antiviral treatment. Being one of the most commonly used tests for CHB patients, ALT level correlates with hepatic necroinflammation. ${ }^{8,20}$ Recent studies showed that TAF-treated patients are more likely to achieve normal on-treatment ALT than TDF-treated patients, despite a similar rate of viral suppression. ${ }^{13,14}$ Yet the exact underlying mechanisms of this observation remain obscured. Persistently elevated ALT in patients with complete viral suppression may imply the co-existence of fatty liver; ${ }^{21}$ it was associated with a lower likelihood of cirrhosis regression in TDF-treated patients. ${ }^{22}$

The clinical impact of ALT normalization at different time points at the first year of NA treatment has been recently studied in 21,182 CHB patients. Approximately half $(10,437 ; 49.3 \%)$ of the patients achieved ALT normalization at 12 months; these patients had reduced the risk of hepatic events for $49 \%$, after adjustment for baseline ALT and other important co-variates. ${ }^{23}$ The cumulative incidence ( $95 \%$ confidence intervals [CI]) of composite hepatic events at 6 years was $3.51 \%(3.06-4.02 \%)$ and $5.70 \%(5.15$ $6.32 \%)$ respectively in patients did or did not achieve ALT normalization at 12 months $(P<0.001)$. Yet it is not the earlier to achieve ALT normalization the better, as the adjusted hazard ratios are comparable for ALT normalization at 3, 6, 9 and 12 months. ${ }^{23}$ There is also a dose-response of on-treatment ALT levels and risk of hepatic events; the higher the ALT levels after 12 months of antiviral treatment, the higher the risk of hepatic events (Fig. 1). ${ }^{23}$

In registration trials of TAF, the independent predictors for achieving ALT normalization included TAF treatment, lower baseline HBV DNA level, negative hepatitis B e antigen (HBeAg) at baseline, male gender and the absence of cirrhosis. ${ }^{13,14}$ On the other hand, patients who had no risk factors for metabolic syndrome (i.e. body mass index $\geq 25 \mathrm{~kg} / \mathrm{m}^{2}$, diabetes, hypertension and hyperlipidaemia) were more likely to achieve ALT normalization. ${ }^{13,14}$ This implies metabolic syndrome and almost certainly fatty liver has a negative impact on ALT normalization in CHB patients. Metabolic syndrome, the strong risk factor of fatty liver, is prognostically important as it is associated with cirrhosis in CHB patients, ${ }^{24}$ liver fibrosis progression, ${ }^{25}$ and even cardiovascular death in CHB patients. ${ }^{26}$

The novel findings concerning the importance of ALT normalization in NA-treated patients have several important clinical implications. We should keep our vigilance for disease progression and HCC in patients with persistent ALT elevation even they are re- ceiving potent NAs with complete viral suppression. We may consider further intervention to reduce risk of hepatic events. Recent studies demonstrated the beneficial effect of statins on CHB patients as it reduces the risk of $\mathrm{HCC}_{1}{ }^{27}$ liver decompensation and death $^{28}$ in patients with chronic viral hepatitis. The remaining unanswered question would be whether ALT normalization leading to reduced risk of hepatic events is a drug-specific phenomenon. The impact of specific NA on normal on-treatment ALT warrants further studies.

\section{UNMET NEED 3: SHALL WE AIM TO ACHIEVE HBsAg SEROCLEARANCE?}

HBsAg seroclearance refers to the loss of detectability of serum $\mathrm{HBsAg}$ with or without antibody to HBsAg (anti-HBs) in CHB patients, which can be achieved spontaneously or induced by antiviral treatment. ${ }^{29}$ The proportion of patients with detectable serum HBV DNA is reported to gradually decrease with time after HBsAg

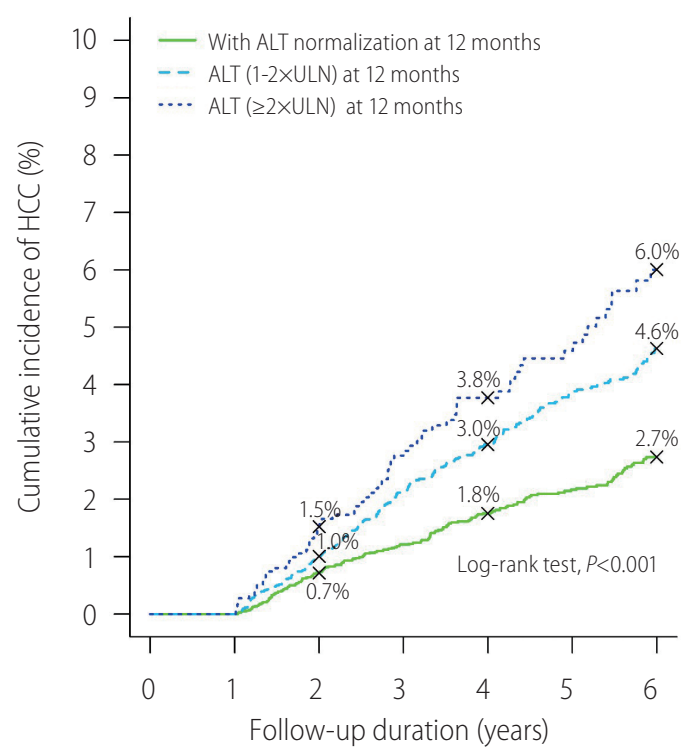

Number at risk

$\begin{array}{llllllll}\text { ALT normalization at } 12 \text { months } & 10,437 & 10,437 & 8,565 & 6,661 & 5,356 & 3,994 & 2,707\end{array}$

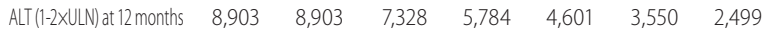

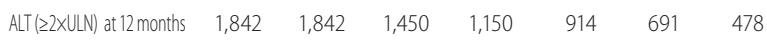

Figure 1. Dose-response of on-treatment alanine aminotransferase (ALT) levels and hepatocellular carcinoma (HCC). There was a dose response in terms of ALT level at 12 months and risk of HCC. Kaplan-Meier analysis estimated the cumulative incidence (95\% confidence interval) of composite endpoint at 6 years in of different ALT levels at 12 months: $<U L N-3.51$ (3.06-4.02); 1-2xULN-5.43 (4.84-6.09); and $\geq 2 x U L N-7.08$ (5.65-8.85; $P<0.001$ for trend). Adopted from Wong et al. ${ }^{23}$ ULN, upper limit of normal. 
seroclearance, ${ }^{30}$ while persistent intrahepatic HBV DNA is detected in some of these patients. ${ }^{31} \mathrm{HBsAg}$ seroclearance is generally a rare event among CHB patients, especially in Asian patients who acquire HBV infection through perinatal transmission. The rate of spontaneous and NA-induced HBsAg seroclearance is found to be comparable in a recent study. ${ }^{29}$ The incidence of HBsAg seroclearance increases with age; the cumulative incidence increases from $1.0 \%$ at 40 years old to as high as $13.9 \%$ at 70 years old. ${ }^{32}$ $\mathrm{HBsAg}$ seroclearance is durable irrespective of the anti-HBs status, as HBsAg seroreversion is uncommon (89/2,211 patients) up to 5 years. $^{29}$

CHB patients who achieve HBsAg seroclearance generally have a favourable clinical course. However, there is still a low yet definite risk of $\mathrm{HCC}$ occurrence. Age and gender play an important role on HCC development after HBsAg seroclearance. A recent study investigated 4,568 Chinese subjects in Hong Kong with $\mathrm{HBsAg}$ seroclearance showed that age older than 50 years old and male gender are two key independent risk factors of HCC development after HBsAg seroclearance (Fig. 2). Compared to the overall annual incidence of $0.3 \%$, male patients who cleared $\mathrm{HBs} A g$ after 50 years old have an HCC incidence of $0.5 \%$ annually. ${ }^{33}$ Preexisting liver cirrhosis and hepatitis $\mathrm{C}$ coinfection are another two well-known risk factors of HCC after HBsAg seroclearance. ${ }^{34} \mathrm{~Pa}$ tients with diabetes mellitus have almost a doubled risk of HCC development after HBsAg seroclearance; diabetic patients with suboptimal glycaemic control of haemoglobin A1c ( $\mathrm{HbA1c}) \geq 7 \%$ over time are further associated with a higher risk of HCC, with an annual incidence of $0.8 \% .^{35}$

Due to the low absolute risk of HCC occurrence in patients with $\mathrm{HBsAg}$ seroclearance, identification of high risk group of HCC development is important for cost-effective HCC surveillance program. HCC surveillance is considered to be cost-effective when the annual risk of HCC exceeds $0.2 \%$ in CHB patient according to American Association for the Study of Liver Diseases (AASLD) guideline. ${ }^{36}$ Thus, male patients who lost HBsAg after 50 years old as well as diabetic patients with suboptimal glycaemic control of $\mathrm{HbA} 1 \mathrm{c} \geq 7 \%$ over time may deserve regular check-up for HCC. ${ }^{33,35}$ Additionally, HCC risk scoring system developed for CHB patients performs reasonably well with high negative predictive value in patients with HBsAg seroclearance. ${ }^{33}$

\section{UNMET NEED 4: DO WE NEED PRE-EMPTIVE ANTIVIRAL TREATMENT TO REDUCE MOTHER- TO-CHILD TRANSMISSION (MTCT)?}

Vertical or MTCT was one of the important transmission routes of HBV before the era of universal vaccination. ${ }^{37}$ Immunoprophylaxis including hepatitis $B$ vaccine and hepatitis B immunoglobulin (HBlg) effectively prevents MTCT of HBV. ${ }^{38}$ Despite the dramatic reduction of $\mathrm{MTCT}$, it still happens, in particulars in babies born to HBeAg-positive mother of high viral load. ${ }^{39}$ A Taiwanese study demonstrated that the maternal serum HBV DNA level of 7, 8, and $9 \log _{10}$ copies $/ \mathrm{mL}$ led to a MTCT rate of HBV $6.6 \%(95 \% \mathrm{Cl}, 0.5$ -

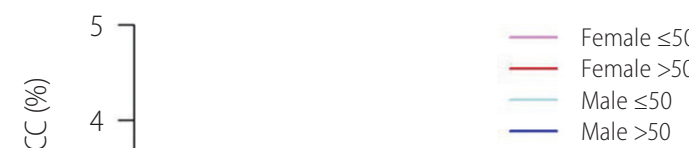

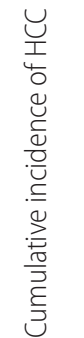

$$
0
$$$$
\text { - }
$$

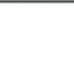

Number at risk

Female $\leq 50 \quad 545$

Female $>50 \quad 1,149$

Male $\leq 50 \quad 769$

Male $>50 \quad 2,105$

483
899
705
1,651

483

705

1,651
414

718

626

1,325
Log-rank test, $P<0.001$

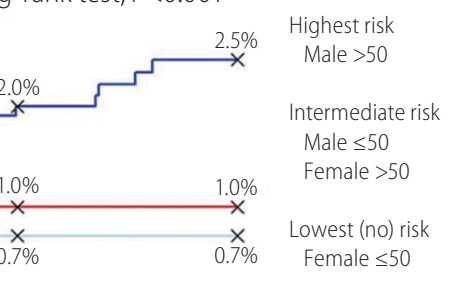

termediate risk

Male $\leq 50$

owest (no) risk

Female $\leq 5$
Figure 2. Impact of age and gender on risk of hepatocellular carcinoma (HCC) after hepatitis B surface antigen ( $\mathrm{HBsAg}$ ) seroclearance. The cumulative incidence rates of $\mathrm{HCC}$ at 1, 3 and 5 years after HBsAg seroclearance were $0.8 \%(0.4 \%$ to $1.6 \%), 1.0 \%(0.5 \%$ to $1.8 \%)$ and $1.0 \%(0.5 \%$ to $1.8 \%)$, respectively in female $>50$ subgroup; the corresponding rates were $0.5 \%$ (0.2\% to $1.4 \%), 0.7 \%(0.3 \%$ to $1.6 \%)$ and $0.7 \%(0.3 \%$ to $1.6 \%)$ in male $\leq 50$ years old subgroup. Adopted from Yip et al. ${ }^{33}$ 
12.6\%; $P=0.033), 14.6 \%(95 \% \mathrm{Cl}, 5.6-23.6 \% ; P=0.001)$, and $27.7 \%(95 \% \mathrm{Cl}, 13.1-42.4 \% ; P<0.001)$, respectively, compared to those below $4 \log _{10}$ copies $/ \mathrm{mL}^{40}$ Maternal serum HBsAg levels of $4,4.5$, and $5 \log _{10} \mathrm{IU} / \mathrm{mL}$ led to a MTCT rate of $2.4 \%(95 \% \mathrm{Cl}$, $0.1-4.6 \% ; P=0.04), 8.6 \%(95 \% \mathrm{Cl}, 4.5-12.7 \% ; P<0.001)$, and $26.4 \%(95 \% \mathrm{Cl}, 12.6-40.2 \% ; P<0.001)$, respectively. Pregnant women with a high $\mathrm{HBsAg}$ level (i.e. above $4-4.5 \log _{10} \mathrm{IU} / \mathrm{mL}$ ) are recommended to receive antiviral therapy. ${ }^{41}$ Antiviral drugs of telbivudine and TDF were considered safety for those high-risk pregnant women to reduce MTCT of HBV. ${ }^{42}$

Two recent landmark randomized trials, one from China (Pan et al.) and one from Thailand (Jourdain et al.) compared TDF to placebo or no antiviral treatment during the third trimester on reducing MTCT of HBV in fully vaccinated infants. ${ }^{43,44}$ Interestingly the Chinese study was a positive one, while the Thai study was a negative one. Per-protocol analysis showed that the MTCT rate was $0 \%$ vs. $7 \%(P=0.01)$ in TDF vs. no antiviral treatment in the Chinese study; whereas that in the Thai study was $0 \%$ vs. $2 \%$ $(P=0.12)$. The reasons resulting in discrepancies of conclusions were the differences in study design of trials, in particulars the timing and intensity of HBV vaccination. In the study by Pan et al., all infants received $10 \mu \mathrm{g}$ of HBV vaccine within 6 hours after birth and received another two vaccines at weeks 4 and 24; on top 200 units of HBlg was given to infants at time of birth and week $4 .{ }^{44}$ On the other hand, in the Thai study, the birth dose of the $10 \mu \mathrm{g} \mathrm{HBV}$ vaccine was given much sooner, within a median time of 1.2 hours after birth; with another 4 doses at months 1,2 , 4 , and 6; in contrast only one dose of HBlg was given to newborn infants within 1.3 hours. Whereas both studies had similar favourable safety profile of TDF in mothers and infants (Table 1).

The CHB management guidelines by the Asian Pacific Association for the Study of Liver (APASL) in 2016, by the EASL in 2017 and by AASLD in 2018 recommended that pregnant women with high serum HBV DNA level should receive antiviral treatment (TDF) at the third trimester in order to reduce MTCT of HBV.,45,46 The threshold of maternal viral load to start antiviral treatment differed between these three guidelines. AASLD guidelines set the threshold at above $200,000 \mathrm{IU} / \mathrm{mL}$ at the second trimester. EASL practice guideline in 2017 also included serum HBsAg levels $>4 \log _{10} \mathrm{IU} / \mathrm{mL}$ and recommended to start antiviral treatment a bit earlier at 24 to 28 weeks of gestation. APASL guidelines proposed a slightly higher threshold of maternal viral load above 6-7 $\log _{10} \mathrm{IU} / \mathrm{mL}$ to receive TDF starting from 28 to 32 weeks of gestation. AASLD and EASL guidelines recommended women with cirrhosis to receive TDF treatment and did not advise against breastfeeding, which was not recommended by APASL guideline such that antiviral drugs should be stopped when breastfeeding starts (Table 2). Study by Beasley et al. showed that breastfeeding does not increase the risk of MTCT. ${ }^{47}$

During pregnancy, HBV activity may increase significantly, especially for women who stopped lamivudine. ${ }^{48}$ The study by ter Borg et al. found that $45 \%$ of ladies had a significant increase in liver disease activity after pregnancy, compared with the expected hepatic flare risk of $27 \%$ in HBeAg positive patients. ${ }^{48}$ AASLD, APASL and EASL guidelines recommended different time for stopping antiviral treatment in pregnant women (Table 2). ${ }^{7,45,46}$ APASL guidelines recommended pregnant women may stop NAs treatment at birth and the time of breastfeeding starts. EASL guide-

Table 1. Comparison between two clinical trials on prevention of mother-to-child transmission of hepatitis B virus

\begin{tabular}{|c|c|c|}
\hline & Chinese & Thailand \\
\hline Design & Open-labelled, randomized & Double blinded, placebo-controlled, randomized \\
\hline Inclusion & $\begin{array}{c}\text { HBeAg positive, } \\
\text { HBV DNA }>200,000 \mathrm{IU} / \mathrm{mL}\end{array}$ & $\begin{array}{l}\text { HBeAg positive, } \\
\text { ALT }<60 \mathrm{U} / \mathrm{L}\end{array}$ \\
\hline HBV DNA & $8.2 \log ($ TDF) vs. $8.0 \log$ (Control) & $7.6 \log (T D F)$ vs. $7.3 \log$ (Placebo) \\
\hline Viruses & Genotype C wild-type with no genotypic mutations & Genotype B with no TDF-resistance mutations \\
\hline Start of antiviral & At week 30-32 & At week 28 \\
\hline Vaccine & 3 doses (month $0,1,6$ )+HBlg & 5 doses (month 0, 1, 2, 4, 6)+HBlg \\
\hline First dose & Within 6 hours & 1.2 (IQR: 0.7-2.2) hours \\
\hline Breast-feeding & No & Yes \\
\hline Mode of delivery (\%) & Caesarean section (53\%) & Caesarean section (26\%) \\
\hline
\end{tabular}

HBeAg, hepatitis B e antigen; HBV, hepatitis B virus; ALT, alanine aminotransferase; TDF, tenofovir disoproxil fumarate; HBlg, hepatitis B immunoglobulin; IQR, interquartile range. 
Table 2. International guidelines on management of pregnancy in ladies with chronic hepatitis B

\begin{tabular}{|c|c|c|c|}
\hline Antiviral therapy & EASL 2017 & AASLD 2018 & APASL 2016 \\
\hline When to start & $\begin{array}{l}\text { In all pregnant women with high } \\
\text { HBV DNA levels }(200,000 \mathrm{IU} / \mathrm{mL} \text { ) or } \\
\text { HBsAg levels ( } 4 \log _{10} \mathrm{IU} / \mathrm{mL} \text { ), antiviral } \\
\text { prophylaxis with TDF should start } \\
\text { at week } 24-28 \text { of gestation (Level 1, } \\
\text { Grade 1) }\end{array}$ & $\begin{array}{l}\text { The AASLD suggests antiviral therapy } \\
\text { to reduce the risk of perinatal } \\
\text { transmission of hepatitis B in HBsAg- } \\
\text { positive pregnant women with an } \\
\text { HBV DNA level }>200,000 \mathrm{lU} / \mathrm{mL} \text {. (C1) }\end{array}$ & $\begin{array}{l}\text { Short-term maternal NA starting } \\
\text { from } 28 \text { to } 32 \text { weeks of gestation is } \\
\text { recommended using either tenofovir } \\
\text { or telbivudine for those mothers with } \\
\text { HBV DNA >6-7 } \log _{10} \mathrm{IU} / \mathrm{mL} \text {. (B2) }\end{array}$ \\
\hline When to stop & $\begin{array}{l}\text { May be continued up to } 12 \text { weeks after } \\
\text { delivery (Level 1, Grade 1) }\end{array}$ & $\begin{array}{l}\text { Antiviral therapy was discontinued at } \\
\text { birth or up to } 4 \text { weeks postpartum. } \\
\text { With discontinuation of treatment, } \\
\text { women should be monitored closely } \\
\text { for up to } 6 \text { months for hepatitis flares } \\
\text { and seroconversion. (C1) }\end{array}$ & $\begin{array}{l}\text { The NAs could be stopped at birth and } \\
\text { when breastfeeding starts, if there is } \\
\text { no contraindication to stopping NAs. } \\
\text { (B2) }\end{array}$ \\
\hline
\end{tabular}

EASL, European Association for the study of the Liver; AASLD, American Association for the Study of Liver Diseases; APASL, Asian Pacific Association for the Study of Liver; HBV, hepatitis B virus; HBsAg, hepatitis B surface antigen; TDF, tenofovir disoproxil fumarate; NA, nucleos(t)ide analogues.

lines advised that those patients may continue antiviral therapy for up to 12 weeks after delivery. Antiviral therapy be discontinued at birth or up to 4 weeks postpartum were recommended by AASLD guideline.

\section{UNMET NEED 5: IS ANTIVIRAL RESISTANCE STILL AN ISSUE?}

Lamivudine, ADV and telbivudine are well known to have low genetic barrier to drug resistance mutation. Hence combination of these antiviral drugs should be avoided to prevent potential inappropriate viral suppression and the emergence of multidrug resistant strains. ${ }^{45}$ The current first-line NA including ETV, TDF and TAF are all highly potent for HBV viral suppression as well as have high barrier to drug resistance mutation. ${ }^{45}$ The cumulative incidence of HBV resistance for ETV was $0.2 \%$ and $0.5 \%$ at first two years and remained $1.2 \%$ during the following three years. Two trials showed that there was no evidence of TDF resistance for five years and after 8 years of treatment relatively. TAF treatment also had no resistance at first two years. ${ }^{45}$

Despite the wide availability of ETV and TDF, drug resistance is still an issue nowadays in many parts of the world. The study by Ning et al. pointed that inadequate education of physicians was one of the important facts leading to the high epidemiology of HBV infection in China. Lamivudine was still considered as a firstline treatment option in some of Asia. ${ }^{49}$ In terms of the Asian-Pacific consensus statement, once patients treated with NAs with low genetic barrier which has led to drug resistance mutations, they should receive NAs without cross-resistance on or before
HBV DNA increased over $2 \times 10^{6} \mathrm{IU} / \mathrm{mL}$ as soon as possible. ${ }^{50}$

Patients with lamivudine resistance are suggested to switch to TDF. Switching to high-dose ETV (1 mg daily) is a second-line option for these patients. If patients have ETV resistance, they are suggested to add TDF. Patients with ADV resistance are recommended to switch to TDF or add lamivudine, telbivudine, ETV. Switching to TDF is indicated for patients with telbivudine resistance. Patients with prior failure of or resistance to lamivudine or telbivudine and ADV are indicated to switch to ETV combine TDF. ${ }^{6,50}$

Patients who have been exposed to various NAs with low genetic barrier to drug resistance may develop multidrug resistance (MDR). To treat MDR, ETV plus TDF is probably the most potent antiviral regimen; yet it may not necessarily achieve better viral suppression compared to TDF monotherapy. ${ }^{51}$ A study from Korea by Lim et al. compared the safe and virologic response of TDF monotherapy and TDF/ETV combined therapy for HBV patients with multiple drug resistance. ${ }^{52}$ The results indicated that there were no new resistance mutations detected and the virologic response of two groups was not significantly different. TDF monotherapy was similar with TDF/ETV combined therapy which was considered an effective treatment for antiviral resistance. After 144 weeks' treatment, patients with HBV DNA levels $<15 \mathrm{IU} / \mathrm{mL}$ occupied 79.4\% (143/180), which was higher than that at week 48.

To sum up, antiviral resistance is still an important issue worldwide. There are many patients previously treated with low barrier of resistance including lamivudine, telbivudine or ADV which could lead to antiviral resistance and they are at risk of cirrhosis development, HCC and death. Newest agents should be widely used to replace suboptimal treatment to reduce drug resistance. Switching to high barrier resistance antiviral drugs is a method to tackle MDR. 


\section{CONCLUSIONS}

The unmet needs of CHB management have been addressed with the availability of potent and safe NAs. The next step of improvement should be increasing the rate of functional cure of $\mathrm{CHB}$ with a finite duration of antiviral treatment. This is going to fulfil the proposed targets set by World Health Organization for the reduction of chronic viral hepatitis incidence and mortality of $80 \%$ and $65 \%$ respectively by $2030 .^{46}$

\section{Authors' contribution}

Both authors were responsible for the interpretation of data, the drafting, and critical revision of the manuscript for important intellectual content.

\section{Conflicts of Interest}

Lilian Yan Liang has no conflicts to disclose.

Grace Lai-Hung Wong has served as a speaker for Abbott, Abbvie, Bristol-Myers Squibb, Echosens, Furui, Gilead and Otsuka, and an advisory committee member for Gilead.

\section{REFERENCES}

1. World Health Organization (WHO). Hepatitis B Fact Sheet N204: Hepatitis B. WHO web site, <https://www.who.int/en/news-room/ fact-sheets/detail/hepatitis-b>. Accessed 30 Apr 2018.

2. Chan SL, Wong VW, Qin S, Chan HL. Infection and cancer: the case of hepatitis B. J Clin Oncol 2016;34:83-90.

3. Liu K, Choi J, Wong VWS, Lim YS, Wong GLH. Tenofovir treatment reduces hepatocellular carcinoma and deaths in chronic hepatitis $B$ patients with liver cirrhosis. Hepatol Int 2017;11(Suppl 1):S84.

4. Wong GL, Chan HL, Mak CW, Lee SK, Ip ZM, Lam AT, et al. Entecavir treatment reduces hepatic events and deaths in chronic hepatitis B patients with liver cirrhosis. Hepatology 2013;58:1537-1547.

5. Lok AS, Zoulim F, Dusheiko G, Ghany MG. Hepatitis B cure: from discovery to regulatory approval. Hepatology 2017;66:1296-1313.

6. European Association for the Study of the Liver. EASL Clinical Practice Guidelines: management of hepatocellular carcinoma. J Hepatol 2018;69:182-236.

7. Sarin SK, Kumar M, Lau GK, Abbas Z, Chan HL, Chen CJ, et al. Asian-Pacific clinical practice guidelines on the management of hepatitis B: a 2015 update. Hepatol Int 2016;10:1-98.

8. Terrault NA, Lok ASF, McMahon BJ, Chang KM, Hwang JP, Jonas $M M$, et al. Update on prevention, diagnosis, and treatment of chronic hepatitis B: AASLD 2018 hepatitis B guidance. Hepatology
2018;67:1560-1599.

9. Wong GL, Seto WK, Wong VW, Yuen MF, Chan HL. Review article: long-term safety of oral anti-viral treatment for chronic hepatitis $B$. Aliment Pharmacol Ther 2018:47:730-737.

10. Wong GL, Tse YK, Wong VW, Yip TC, Tsoi KK, Chan HL. Long-term safety of oral nucleos(t)ide analogs for patients with chronic hepatitis B: a cohort study of 53,500 subjects. Hepatology 2015;62:684-693.

11. Rodríguez-Nóvoa S, Labarga P, Soriano V, Egan D, Albalater M, Morello J, et al. Predictors of kidney tubular dysfunction in HIV-infected patients treated with tenofovir: a pharmacogenetic study. Clin Infect Dis 2009;48:e108-e116.

12. Wong GL, Chan HL, Tse YK, Yip TC, Lam KL, Lui GC, et al. Chronic kidney disease progression in patients with chronic hepatitis $B$ on tenofovir, entecavir, or no treatment. Aliment Pharmacol Ther 2018:48:984-992.

13. Buti M, Gane E, Seto WK, Chan HL, Chuang WL, Stepanova T, et al. Tenofovir alafenamide versus tenofovir disoproxil fumarate for the treatment of patients with $\mathrm{HBeAg}$-negative chronic hepatitis $\mathrm{B}$ virus infection: a randomised, double-blind, phase 3, non-inferiority trial. Lancet Gastroenterol Hepatol 2016;1:196-206.

14. Chan HL, Fung S, Seto WK, Chuang WL, Chen CY, Kim HJ, et al. Tenofovir alafenamide versus tenofovir disoproxil fumarate for the treatment of $\mathrm{HBeAg}$-positive chronic hepatitis B virus infection: a randomised, double-blind, phase 3, non-inferiority trial. Lancet Gastroenterol Hepatol 2016;1:185-195.

15. Scott LJ, Chan HLY. Tenofovir alafenamide: a review in chronic hepatitis B. Drugs 2017;77:1017-1028.

16. Agarwal K, Brunetto M, Seto WK, Lim YS, Fung S, Marcellin P, et al. 96 weeks treatment of tenofovir alafenamide vs. tenofovir disoproxil fumarate for hepatitis B virus infection. J Hepatol 2018;68:672-681.

17. Fung S, Yatsuhashi H, Tak WY, Celen MK, Flaherty JF, Kim K, et al. Features of the metabolic syndrome are associated with lack of serum ALT normalization during therapy for chronic hepatitis B [Abstract]. Hepatology 2016;64(1 Suppl):914A-915A.

18. Chan HL, Fung S, Seto WK, Gane E, Flaherty JF, Suri V, et al. Improved bone and renal safety of switching from tenofovir disoproxil fumarate to tenofovir alafenamide: preliminary results from 2 phase 3 studies in $\mathrm{HBeAg}$-positive and $\mathrm{HBeAg}$-neagtive patients with chronic hepatitis B. J Hepatol 2017;66(Suppl):S25.

19. Wong GL, Tse YK, Yip TC, Chan HL, Tsoi KK, Wong VW. Long-term use of oral nucleos(t)ide analogues for chronic hepatitis $B$ does not increase cancer risk - a cohort study of 44494 subjects. Aliment Pharmacol Ther 2017;45:1213-1224.

20. Chan HL, Hui Y, Leung NW, Ching JY, Chan FK, Sung JJ. Risk factors for active liver disease in HBeAg-negative chronic hepatitis B virusinfected patients. Am J Gastroenterol 2000;95:3547-3551.

21. Wong VW, Wong GL, Chu WC, Chim AM, Ong A, Yeung DK, et al. Hepatitis $B$ virus infection and fatty liver in the general population. $J$ 
Hepatol 2012;56:533-540.

22. Marcellin P, Gane E, Buti M, Afdhal N, Sievert W, Jacobson IM, et al. Regression of cirrhosis during treatment with tenofovir disoproxil fumarate for chronic hepatitis B: a 5-year open-label follow-up study. Lancet 2013;381:468-475.

23. Wong GL, Chan HL, Tse YK, Yip TC, Lam KL, Lui GC, et al. Normal on-treatment ALT during antiviral treatment is associated with a lower risk of hepatic events in patients with chronic hepatitis B. J Hepatol 2018;69:793-802.

24. Wong GL, Wong VW, Choi PC, Chan AW, Chim AM, Yiu KK, et al. Metabolic syndrome increases the risk of liver cirrhosis in chronic hepatitis B. Gut 2009;58:111-117.

25. Wong GL, Chan HL, Yu Z, Chan AW, Choi PC, Chim AM, et al. Coincidental metabolic syndrome increases the risk of liver fibrosis progression in patients with chronic hepatitis B--a prospective cohort study with paired transient elastography examinations. Aliment Pharmacol Ther 2014;39:883-893.

26. Cheng JY, Wong VW, Tse YK, Chim AM, Chan HL, Wong GL. Metabolic syndrome increases cardiovascular events but not hepatic events and death in patients with chronic hepatitis B. Hepatology 2016;64:1507-1517.

27. Hsiang JC, Wong GL, Tse YK, Wong VW, Yip TC, Chan HL. Statin and the risk of hepatocellular carcinoma and death in a hospitalbased hepatitis B-infected population: a propensity score landmark analysis. J Hepatol 2015;63:1190-1197.

28. Wong JC, Chan HL, Tse YK, Yip TC, Wong VW, Wong GL. Statins reduce the risk of liver decompensation and death in chronic viral hepatitis: a propensity score weighted landmark analysis. Aliment Pharmacol Ther 2017;46:1001-1010.

29. Yip TC, Wong GL, Wong VW, Tse YK, Lui GC, Lam KL, et al. Durability of hepatitis $B$ surface antigen seroclearance in untreated and nucleos(t)ide analogue-treated patients. J Hepatol. 2017 Oct 6. pii: S0168-8278(17)32332-2. doi: 10.1016/j.jhep.2017.09.018.

30. Yuen MF, Wong DK, Fung J, Ip P, But D, Hung I, et al. HBsAg Seroclearance in chronic hepatitis $B$ in Asian patients: replicative level and risk of hepatocellular carcinoma. Gastroenterology 2008;135:1192-1199.

31. Loriot MA, Marcellin P, Walker F, Boyer N, Degott C, Randrianatoavina $I$, et al. Persistence of hepatitis $B$ virus DNA in serum and liver from patients with chronic hepatitis B after loss of HBsAg. J Hepatol 1997:27:251-258.

32. Yip TC, Wong VW, Tse YK, Chan HL, Wong GL. Hepatitis B surface antigen seroclearance in a cohort of 154,740 patients with chronic hepatitis B: a 15-year follow-up study. Hepatol Int 2017;11:S75.

33. Yip TC, Chan HL, Wong VW, Tse YK, Lam KL, Wong GL. Impact of age and gender on risk of hepatocellular carcinoma after hepatitis $B$ surface antigen seroclearance. J Hepatol 2017;67:902-908.

34. Ahn SH, Park YN, Park JY, Chang HY, Lee JM, Shin JE, et al. Long- term clinical and histological outcomes in patients with spontaneous hepatitis B surface antigen seroclearance. J Hepatol 2005;42:188-194.

35. Yip TCF, Wong VWS, Chan HLY, Tse YK, Kong APS, Lam KLY, et al. Effects of diabetes and glycemic control on risk of hepatocellular carcinoma after seroclearance of hepatitis B surface antigen. Clin Gastroenterol Hepatol 2018;16:765-773.e2.

36. Bruix J, Sherman M; American Association for the Study of Liver Diseases. Management of hepatocellular carcinoma: an update. Hepatology 2011;53:1020-1022.

37. Cui Y, Jia J. Update on epidemiology of hepatitis B and C in China. J Gastroenterol Hepatol 2013;28 Suppl 1:7-10.

38. Lee C, Gong Y, Brok J, Boxall EH, Gluud C. Effect of hepatitis B immunisation in newborn infants of mothers positive for hepatitis B surface antigen: systematic review and meta-analysis. BMJ 2006;332:328-336.

39. Wen WH, Chen HL, Ni YH, Hsu HY, Kao JH, Hu FC, et al. Secular trend of the viral genotype distribution in children with chronic hepatitis B virus infection after universal infant immunization. Hepatology 2011;53:429-436.

40. Wen WH, Chang MH, Zhao LL, Ni YH, Hsu HY, Wu JF, et al. Motherto-infant transmission of hepatitis $B$ virus infection: significance of maternal viral load and strategies for intervention. J Hepatol 2013;59:24-30

41. Wen WH, Huang CW, Chie WC, Yeung CY, Zhao LL, Lin WT, et al. Quantitative maternal hepatitis B surface antigen predicts maternally transmitted hepatitis B virus infection. Hepatology 2016;64:1451-1461.

42. Brown RS Jr, McMahon BJ, Lok AS, Wong JB, Ahmed AT, Mouchli $M A$, et al. Antiviral therapy in chronic hepatitis $B$ viral infection during pregnancy: a systematic review and meta-analysis. Hepatology 2016;63:319-333.

43. Jourdain G, Ngo-Giang-Huong N, Harrison L, Decker L, Khamduang $W$, Tierney $C$, et al. Tenofovir versus placebo to prevent perinatal transmission of hepatitis B. N Engl J Med 2018;378:911-923.

44. Pan CQ, Duan Z, Dai E, Zhang S, Han G, Wang Y, et al. Tenofovir to prevent hepatitis $B$ transmission in mothers with high viral load. N Engl J Med 2016;374:2324-2334.

45. European Association for the Study of the Liver. EASL 2017 Clinical Practice Guidelines on the management of hepatitis B virus infection. J Hepatol 2017;67:370-398.

46. World Health Organization (WHO). Combating hepatitis B and C to reach elimination by 2030. WHO web site, <http://www.who.int/ hepatitis/publications/hep-elimination-by-2030-brief/en/>. Accessed 1 Nov 2018.

47. Beasley RP, Stevens CE, Shiao IS, Meng HC. Evidence against breastfeeding as a mechanism for vertical transmission of hepatitis $B$. Lancet 1975;306:740-741.

48. ter Borg MJ, Leemans WF, de Man RA, Janssen HL. Exacerbation of chronic hepatitis B infection after delivery. J Viral Hepat 2008;15:37-41. 
49. Ning LH, Hao J, Liao ZL, Zhou YY, Guo H, Zhao XY. A survey on the current trends in the management of hepatitis B in China. Eur J Gastroenterol Hepatol 2012;24:884-889.

50. Liaw YF, Kao JH, Piratvisuth T, Chan HL, Chien RN, Liu CJ, et al. Asian-Pacific consensus statement on the management of chronic hepatitis B: a 2012 update. Hepatol Int 2012;6:531-561.

51. Lee YB, Lee JH, Lee $D H$, Cho $H$, Ahn H, Choi WM, et al. Efficacy of entecavir-tenofovir combination therapy for chronic hepatitis B patients with multidrug-resistant strains. Antimicrob Agents Chemother 2014;58:6710-6716.

52. Lim YS, Lee YS, Gwak GY, Byun KS, Kim YJ, Choi J, et al. Monotherapy with tenofovir disoproxil fumarate for multiple drug-resistant chronic hepatitis B: 3-year trial. Hepatology 2017;66:772-783. 